Journal of Current and Advance Medical Research

July 2018, Vol. 5, No. 2, pp. 60-63

http://www.banglajol.info/index.php/JCAMR

ISSN (Print) 2313-447X

ISSN (Online) 2413-323X

DOI: http://dx.doi.org/10.3329/jcamr.v5i2.37061

ORIGINAL ARTICLE

OPEN@ACCESS

\title{
Associated Valvular Heart Diseases among ASD Patients Undergoing Surgical Repair
}

\author{
Ratna Rani Roy ${ }^{1}$, Pankaj Kumar Saha ${ }^{2}$, Mohammad Abdullah Yusuf ${ }^{3}$, Haridas Saha ${ }^{4}$, \\ Md. Ibnul Hasan ${ }^{5}$, Rajib Dey Sarkar ${ }^{6}$
}

\begin{abstract}
${ }^{1}$ Associate Professor, Department of Anatomy, Dr. Sirajul Islam Medical College, Dhaka, Bangladesh; ${ }^{2}$ Professor \& Head, Department of Surgery, Shaheed Suhrawardy Medical College, Dhaka, Bangladesh; ${ }^{3}$ Assistant Professor, Department of Microbiology, National Institute of Neurosciences \& Hospital, Dhaka, Bangladesh; ${ }^{4}$ Assistant Professor, Department of Surgery, Dhaka Medical College, Dhaka, Bangladesh; ${ }^{5}$ Junior Consultant (Surgery), Upazila Health Complex, Sokhipur, Tangail, Bangladesh; ${ }^{6}$ Register, Department of Surgery, Shaheed Suhrawardy Medical College, Dhaka, Bangladesh
\end{abstract}

[Received on: 21 April 2018; Reviewed on: 3 May 2018; Accepted on: 1 June 2018; Published on: 1 July 2018]

\section{Abstract}

Background: Congenital heart diseases (CHD) are one of the most common developmental errors in humans. Objectives: The purpose of the present study was to see the frequencies of various types of atrial septal defect (ASD) and associated cardiovascular disorders in patients undergoing surgical repair. Methodology: This cross-sectional study was conducted on patients undergoing surgical repair at the National Institute of Cardiovascular Diseases (NICVD) or the National Heart Foundation and Research Institute (NHF \& RI) in Dhaka, during the period of July, 2010 to June, 2011. Patients presented with ASD at any age of both sexes were selected as study population. Diagnoses were revealed with echocardiography and confirmed preoperatively by registered cardiac surgeons. Results: The morphological types of ASD were ostium secundum type in $96 \%$ cases and sinus venosus type in $4 \%$ cases. Atrial septal defects were either small or larger defects associated with pulmonary hypertension in $38(76 \%)$ cases, varying degree of tricuspid regurgitation was seen in $33(66 \%)$ patients and dilated pulmonary artery was noted in $24(48 \%)$ cases. Ventricular septal defect in $4(8 \%)$ cases, tricuspid atresia in $2(4 \%)$ cases and mitral valve prolapse in $6(12 \%)$ cases were also observed. Conclusions: Ostium secundum type of ASD is found to be the commonest type of ASD. [Journal of Current and Advance Medical Research 2018;5(2):60-63]

Keywords: Atrial septal defect; echocardiography; ostium secundum; sinus venosus; tricuspid regurgitation; tricuspid atresia; ventricular septal defect; mitral valve prolapse

Correspondence: Dr. Ratna Rani Roy, Associate Professor, Department of Anatomy, Dr. Sirajul Islam Medical College, Dhaka, Bangladesh; Email:ratnaraniroy@yahoo.com; cell no.: +8801711248109

Cite this article as: Roy RR, Saha PK, Yusuf MA, Saha H, Hasan MI, Sarkar RD. Associated Valvular Heart Diseases among ASD Patients Undergoing Surgical Repair. J CurrAdv Med Res 2018;5(2):60-63

Funding: This study has been performed without any funding from outside else.

Conflict of Interest: There was no conflict of interest to any of the authors.

Contributions to authors: Roy RR have contributed in protocol preparation, data collection, data analysis upto the report writing; Roy RR, Saha PK, Yusuf MA, Saha H, Hasan MI, Sarkar RD have written \& revised the manuscript.

Copyright: (02018. Roy et al. Published by Journal of Current and Advance Medical Research. This article is published under the Creative Commons CC BY-NC License (https://creativecommons.org/licenses/by-nc/4.0/). This license permits use, distribution and reproduction in any medium, provided the original work is properly cited, and is not used for commercial purposes. 


\section{Introduction}

Congenital heart disease is a gross structural abnormality of the heart or great vessels that is actually or potentially of functional significance ${ }^{1}$. ASD is one of the most common congenital heart defects in adults $^{2}$. In Bangladesh, among the hospitalized children with CHD, the largest share (70\%) is occupied by left to right shunt anomalies ${ }^{3}$. Among them, ASD is the second most common; left to right shunt anomalies of the children is also common among the admitted patients in CHD hospital. The incidence of ASD among CHD in the live born is $7.4 \%{ }^{4}$.

A study was carried out over a period of 3 years (2004 to 2006) on the 5,668 live births and found that lesions among these babies were ASD (26.0\%), ventricular septal defect or VSD (16.9\%), patent ductus arteriosus or PDA (18\%) and tetralogy of Fallot or TOF $(14.0 \%)^{5}$. ASD diagnosis depends on symptoms, signs, noninvasive and invasive investigations. ASD may be of different types by their physical and functional characteristics.

However, there is no adequate reporting on the morphological types of ASD and other associated cardiovascular disorders in the Bengali population of Bangladesh is lacking. Considering the above points, the present study is designed to determine the different morphological types of ASD and associated cardiovascular disorders distributed among Bangladeshi patients undergoing surgical repair.

\section{Methodology}

This cross-sectional descriptive study was carried out from July, 2010 to June, 2011 at the National Institute of Cardiovascular Diseases (NICVD) or the National Heart Foundation and Research Institute (NHF \& RI) in Dhaka. ASD patients diagnosed by registered cardiac surgeons of either sex undergoing surgical repair through convenience sampling technique were enrolled for this study. An informed consent was taken from patients or one of the parents in case of minors. Examinations of hospital records of patients were used for identifying the morphological types of ASD and associated cardiovascular disorders determined by the registered cardiologists at echocardiography. The associated cardiovascular disorders were also detected using 2-D M mode color Doppler echocardiography. Per-operative photographs of the defect were taken from the above patients. The classification was also confirmed pre-operatively by the registered cardiac surgeons. The data were recorded in a predesigned data collection sheet. Statistical analysis was performed by SPSS version 20.0. The qualitative data were expressed as frequency and percentage. All the data were meticulously checked and were analyzed.

\section{Results}

A total number of 50 patients were recruited for this study. The mean age of the study sample of the 50 ASD patients was $19.9 \pm 11.16$ years (mean \pm $\mathrm{SD})$, with an age range of 2 months to 45 years. Majority of the study population were in the age group of 21 to 30 years which was 19 patients. There were $19(38 \%)$ males and $31(62 \%)$ females.Male-female ratio was 1:1.9 (Table 1).

\section{Table1: Age and sex distribution of patients $(n=$} 50)

\begin{tabular}{|l|c|c|c|}
\hline Age Group & Male & Female & Total \\
\hline 0 to 10 Years & 3 & 9 & 12 \\
\hline 11 to 20 Years & 4 & 7 & 11 \\
\hline 21 to 30 Years & 9 & 10 & 19 \\
\hline 31 to 40 Years & 2 & 3 & 5 \\
\hline 41 to 50 Years & 1 & 2 & 3 \\
\hline Total & $\mathbf{1 9}$ & $\mathbf{3 1}$ & $\mathbf{5 0}$ \\
\hline
\end{tabular}

Among the 50 patients, only two morphological types of ASD were identified. They were fossa ovalis (ostium secundum) type was found in 48 (96\%) cases and sinus venosus type was found in 2 (4\%) cases (Table 2).

Table2: Different morphological types of ASD $(\mathbf{n}=\mathbf{5 0})$

\begin{tabular}{|l|c|c|}
\hline Types of ASD & Frequency & Percentage \\
\hline Ostium secundum & 48 & 96.0 \\
\hline Sinus venosus & 2 & 4.0 \\
\hline Total & $\mathbf{5 0}$ & $\mathbf{1 0 0 . 0}$ \\
\hline
\end{tabular}

Out of these 33(66\%) were associated with tricuspid valve regurgitation and $3(6 \%)$ patients with VSD contributed to pulmonary stenosis and 2(4\%) had tricuspid valve atresia. Large ASD was associated with mitral valve prolapsed in $6(12 \%)$ cases and most of the patients in this group were below twenty five years (Table 3 ). 
Table 3: Valvular Heart Diseases among ASD Patients

\begin{tabular}{|l|c|c|}
\hline Echo finding & Frequency & Percentage \\
\hline Tricuspid regurgitation & 33 & 66.0 \\
\hline Mitral valve prolapse & 6 & 12.0 \\
\hline Pulmonary stenosis & 3 & 6.0 \\
\hline Tricuspid atresia & 2 & 4.0 \\
\hline Mitral regurgitation & 1 & 2.0 \\
\hline Total & $\mathbf{5 0}$ & $\mathbf{1 0 0 . 0}$ \\
\hline
\end{tabular}

\section{Discussion}

Small atrial communications often close spontaneously, but moderate to large ASDs should be closed typically between ages 2 to 6 years ${ }^{6}$. Moderate and large ASD cause right atrial and ventricular overload, ultimately pulmonary artery hypertension leading to elevated pulmonary vascular resistance, right ventricular hypertrophy, heart failure, and atrial arrhythmias?

In the present study, the commonest age of presentation was second and third decade. Female and male ratio was found in 1.9:1. The predominant type was the ostium secundum out of six varities. The obvious preponderance of the ostium secundum type is almost universal ${ }^{8-13}$. In the United States, it has been noted that about 15.0 to $30.0 \%$ of the healthy adults has an unfused foramen ovale in which the valve functioned normally. It has been observed that sinus venosus ASD constituting 5 to $10 \%$ of all ASDs in their study ${ }^{14}$. In another study it has been reported on a study in the United States in which less than 1.0\% cases were of the coronary sinus type ${ }^{15}$. It has been observed that ostium secundum defects accounts for about $80.0 \%$ of ASDs; the ostium primum type representing $10 \%$ and the sinus venosus type being seen in about $10 \%$ of cases $^{16}$.

In the present study, pulmonary hypertension was seen in $76.0 \%$ patients. Mild to moderate degree of pulmonary hypertension occurs in many ASD patients as a reflection of aging and pulmonary vascular diseases which may occur in up to 5 to $10.0 \%$ of patients with untreated ASDs ${ }^{9}$. It has been found that 41 patients with ASD developed significant pulmonary hypertension. In another study it has been mentioned that the development of pulmonary hypertension can occur at an early age. However, it has found in another study that pulmonary hypertension is unusual before 20 years of age and it is seen in 50\% of individuals above the age of 40 years ${ }^{17}$.
In the present study mitral valve prolapse was found in $12 \%$ of the patients ${ }^{18}$. Mitral valve prolapsed associated with secundum ASD is a functional disorder and recognized in 47 patients. Mitral valve prolapse is encountered at a rate of $25-95 \%$ in patients with atrial septal defect ${ }^{19}$. In current study tricuspid regurgitation was seen in $66.0 \%$ of the patients. Similar finding was noted ${ }^{20}$. However, it has been found that $38 \%$ patient of ASD with congenital tricuspid regurgitation and peripheral pulmonary stenosis ${ }^{20}$.

\section{Conclusion}

Ostium secundum type of ASD is found to be the commonest type of ASD. Pulmonary hypertension was the commonest complication followed by tricuspid regurgitation and dilated pulmonary artery. Mitral valve prolapse was the commonest anomaly followed by ventricular septal defect and tricuspid atresia.

\section{References}

1. Kai H, Koyanagi S, Hirooka Y, Sugimachi M, Sadoshima JI, Suzuki S, et al. Right-to-left shunt across atrial septal defect related to tricuspid regurgitation: assessment by transesophageal Doppler echocardiography. American Heart Journal 1994;127(3), 578-584

2. Kouchoukos NT, Blackstone EH, Doty DB, Hanley FL, Karp RB. Kirklin/Barratt-Boyes cardiac surgery. Vol.1, 3rdedn. Churchill Livingston, USA, 2003

3. Sellke FW, Del Nido PJ, Swanson SJ (eds). Sabiston\& Spencer surgery of the chest. Vol. 2, $8^{\text {th }}$ edn. Elsevier Saunders, Philadelphia, USA, 2010

4. Dickinson DF, Arnold R, Wilkinson JL. Congenital heart disease among 160,480 liveborn children in Liverpool 19601969. Implications of surgical treatment. British Heart Journal 1981;46(1), 55-62

5. Webb G,Gatzoulis MA. Atrial septal defects in the adult. Circulation of American Heart Association 2006;114(15):1645-1653

6. Mahmood M, Haque S KHMS, Ahmed QS, Siddique MA, Ahmed CM. Doppler evaluation of left to right shunt (QP/QS) in patient isolated septal ASD. Chest \& Heart journal 2005;29(1):26-31

7. Doherty GM (ed). Current diagnosis and treatment. 13th edn. McGraw Hill, USA, 2010

8. Sarkozy A, Conti E, Neri C, Agostino RD, Digilio MC, Esposito G, et al. Spectrum of atrial septal defects associated with mutations of NKX2.5 and GATA4 transcription factors. Journal of Medical Genetics, 2005;42(2)

9. Weigers SE, Sutton MGJ. Pathophysiology and clinical features of atrial septal defects in adults. UpTpDate. 2007; 5:3 10. Tanji M, Iwaya F, Igari T, Ogawa T, Takahashi $\mathrm{K}$,Hoshino S. A case of congenital tricuspid regurgitation associated with atrial septal defect and peripheral pulmonary stenosis. Zasshi 1996;44(12):2146-50

11. Fatema NN, Chowdhury RB, Chowdhury L. Incidence of congenital heart disease among hospital live birth in a tertiary hospital of Bangladesh. Cardiovascular Journal 2008;1(1);1420

12. Shah D, Azhar M, Oakley CM, Cleland JGF,Nihoyannopoulos P. Natural history of secundum atrial 
septal defect in adults after medical or surgical treatment: a historical prospective study. British Heart Journal 1994;71(3):224-228

13. Fuster V, Alexander RW \& O'Rourke RA (eds). Hurst's the heart. Vol.1 \& 2, 10th edn. McGraw Hill, USA, 2004

14. Carr MR. Pediatric atrial septal defects. Medscape, 2010

15. Rosas M, Attie F, Sandoval J, et al. Atrial septal defects in adults $\geq 40$ years old: negative impact of low arterial oxygen saturation. International journal of cardiology 2004;93(2-3);145-155

16. Bezold LI 2008. Atrial septal defect, coronary sinus. Medscape.
17. Libby $\mathrm{P}$, Bonow RO, Mann DL \&Zipes DP (eds). Braunwald's heart disease: a textbook of cardiovascular medicine. $8^{\text {th }}$ edn. Saunders Elsevier, Philadelphia, USA,2008 18. Suchoń E, Podolec P, Płazak W, Tomkiewicz-Pajak L, Pieculewicz M, Mura A, et al. Atrial septal defect associated with mitral valve prolapse--prevalence and clinical significance. Przegladlekarski2004;61(6):636-9

19. Numan M. Congenital heart disease - A: isolated atrial septal defect embryology, clinical presentation, and diagnosis. Official journal of gulf heart association, 2002;3(2):5

20. Kestelli M. Mitral valve prolapse in atrial septal defect. The Internet Journal of Cardiology 2001;1(2) 